\title{
Photogrammetry in Depth: Revealing HMS Hampshire
}

\author{
Chris Rowland \\ 3DVisLab. University of Dundee \\ DJCAD, Perth Road, Dundee, Tayside \\ Scotland, UK \\ c.rowland@dundee.ac.uk
}

\author{
Kari Hyttinen \\ Munkkiniemen puistotie 2A13 \\ 00330 Helsinki \\ Finland \\ Kari.hyttinen@me.com
}

\begin{abstract}
HMS Hampshire was a Devonshire Class armoured cruiser that saw action at the Battle of Jutland in 1916. Immediately after the battle, the ship was tasked with transporting Field Marshall Lord Kitchener to Russia on a diplomatic mission. The ship hit mines laid by U-75 approximately 1.5 miles North of Orkney at Birsay Head and sank with a loss of 737 men, including Kitchener and his staff. To commemorate the centenary of the ship's loss, the MoD granted a survey licence to an international team of technical diving and sub-sea imaging specialists in May/June 2016.

This paper will present the results of the diver survey carried out at a depth of 65 metres and describe the challenges of creating accurate 3D images of the wreck using photogrammetry in a deep, dark and hostile environment. The resulting 3D models are presented using immersive virtual reality technology (HTC Vive, Oculus Rift) at real World scale, emulating the diver's experience on the seabed.
\end{abstract}

3D Visualisation. Virtual Reality. Shipwreck. Maritime archaeology. Photogrammetry.

\section{INTRODUCTION}

Creating 3D models of archaeological sites using structure from motion (SfM) is an established and well documented method (Green, Bevan \& Shapland 2014). The simplicity of the process, and the availability of open source photogrammetry tools has facilitated the digital capture of heritage sites around the world. Commercially available tools (e.g. Agisoft Photoscan, Reality Capture and Remake) condense the processes involved into a single streamlined package that simplify the process further. Underwater sites present specific challenges for photogrammetry. They are often difficult to access, require specialist equipment (e.g. camera housings, lights) and diver training. When the site of interest is beyond the safe range of open-circuit scuba equipment, technical dive training, closed circuit rebreathers and mixed gas blends also become necessary.

\subsection{Location}

The wreck of HMS Hampshire lies on the seabed at a depth of 65 metres off Birsay Head to the North of Mainland Orkney. This depth is at the limit of open-circuit diving so the team was selected based on technical diving, rebreather experience in order to achieve the optimum "bottom time" on the wreck.

\subsection{Remote sensing}

Remote sensing technology such as multi-beam sonar and subsea laser are effective methods to survey shipwreck sites without diver involvement. However, these technologies do not capture colour information and the resolution and quality of the point cloud data produced can vary significantly. A sonar survey was carried out prior to the diver expedition by ORCA Marine, University of Highlands and Islands but the resulting data was not made available until 2017. It is intended to use this data as a basic map of the site onto which detailed photogrammetry models can be located.

The focus of the expedition was to gather detailed information that is beyond the current capability of multi-beam sonar so photogrammetry was selected as the most appropriate method to represent the detailed features of the wreck. 


\section{BACKGROUND}

HMS Hampshire was launched in September 1903 (Figure 1). The ship served with the First Cruiser Squadron, the Third Fleet and the Mediterranean Fleet before transferring to the China Station in 1912. After assignment to the Grand Fleet at the end of 1914, HMS Hampshire saw action at the Battle of Jutland. Immediately after Jutland the ship was carrying Lord Kitchener and his senior staff to Arkhangelsk in Russia when she hit a mine laid by U-75. The ship sank within fifteen minutes of the strike with a loss of 746 lives. Only twelve crewmen survived (Campbell 1998).

This project set out to record the condition of the wreck of HMS Hampshire for the centenary commemorations of the sinking (June 2016). The wreck is designated as a controlled site under the UK Protection of Military Remains Act (1986). The protection order has prevented looting of artefacts from the site for thirty years. Prior to the protection order there have been various legal and illegal salvage attempts including the removal of the starboard propeller and associated prop shaft which was recovered and is now on display at Lyness Museum, Orkney.

\subsection{Ministry of Defence Licence}

The MoD granted a survey licence to the expedition team designating Rod Macdonald as the licence holder. Macdonald had previously written about the sinking of HMS Hampshire (Macdonald 2011) and had dived the wreck prior to the protection order. The conditions of the licence prohibited any disturbance of the wreck and artefacts found in its vicinity.

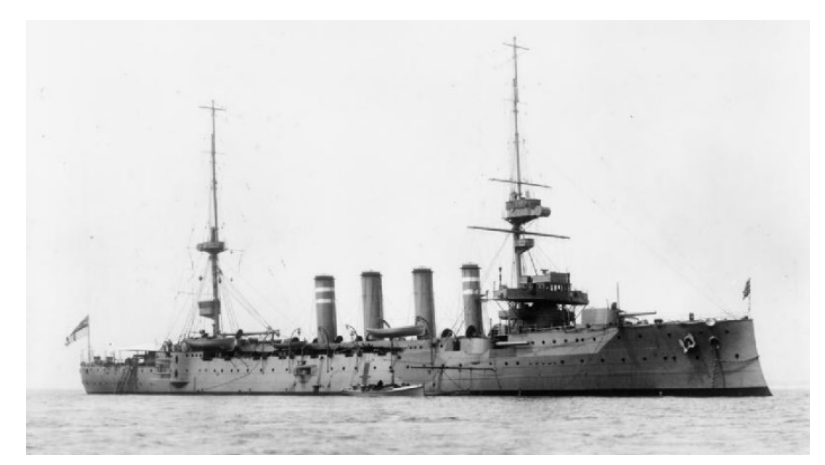

Figure 1: HMS Hampshire (1903) Imperial War Museum.

\section{EXPEDITION}

Macdonald and colleague Paul Haynes organised the expedition to take place from $28^{\text {th }}$ May to $11^{\text {th }}$ June 2016, in association with Orkney based MV Huskyan dive boat operator Emily Turton and Ben Wade. The main expedition objectives were defined as follows;
- Ascertain the present condition of the wreck

- Undertake a detailed survey

- Catalogue the main features of the site with photography, video.

- Post process the main features of the wreck in 3D.

- Produce a survey report

- Raise public awareness of the historical significance of the wreck.

In addition, the team hoped the project would assist in fostering improved relations between the UK Ministry of Defence, the Heritage agencies and the Orkney community.

\subsection{The core team}

The expedition team had defined roles as follows:

- Kari Hyttinen - Photogrammetry.

- Immi Wallin - 3D Lighting.

- Chris Rowland -3D Lighting.

- Marjo Tynkkinen - Photography.

- Emily Turton - Photo lighting.

- Rod Macdonald - Survey.

- Paul Haynes - Survey.

- Ben Wade - Survey.

- Kevin Heath - Side-scan sonar

The team extended to include additional technical divers who were tasked with gathered additional GoPro video footage from targets surrounding the main wreck site. On site these additional members were humorously referred to as the "Expendables" since their tasks could change on a day to day basis. Their input proved valuable in identifying outlying targets that were initially unclear on the side-scan sonar images.

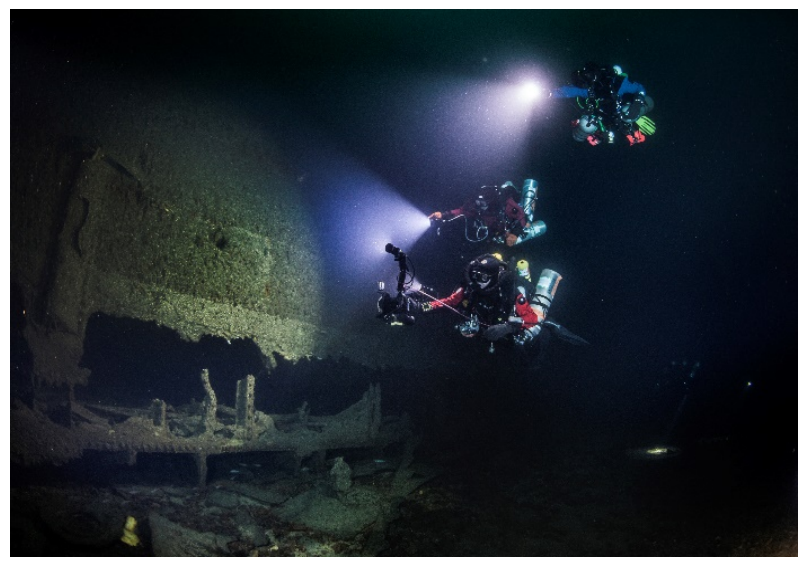

Figure 2: The photogrammetry team on the Port side of the wreck of HMS Hampshire. Photo: M Tynkkynen.

Due to the depth of the wreck $(65 \mathrm{~m})$ and the tidal conditions, only one dive per day was planned. For the photogrammetry team (Hyttinen, Wallin \& Rowland) the plan was to restrict the time on site 
(bottom time) to twenty minutes per dive. This would allow for approximately two hours of ascent time due to decompression requirements i.e. total dive time of $<2.5$ hours per day. Figure 2 shows (top to bottom) Rowland, Wallin and Hyttinen illuminating and recording the Port side of the upturned wreck.

The diving schedule placed the team on the wreck for the first time on Monday $30^{\text {th }}$ May. Underwater visibility at the depth of 65 metres was a minimum of 25 metres (remarkably good for the location). Due to the depth, minimal ambient light reached the wreck. To compensate for this the photogrammetry team carried four primary lights: two 10,000 lumen lights attached to the camera rig, one 32,000 lumen flood light and one 50,000 lumen flood light. A total of 102,000 lumens to provide sufficient illumination to capture video footage with appropriate depth of focus for photogrammetry.

The good weather conditions prevailed for May $31^{\text {st }}$ and June 1st with similar excellent visibility on the wreck. The weather changed for the worse on June 2nd preventing safe access to the site. The three dives carried out during this period produced the best footage for photogrammetry. Diving resumed on June $3^{\text {rd }}$ and proceeded on schedule to June $10^{\text {th }}$. Further video footage and photographs were gathered to capture the remaining features of the wreck. Figure 3 shows the remaining portside propeller at the stern.

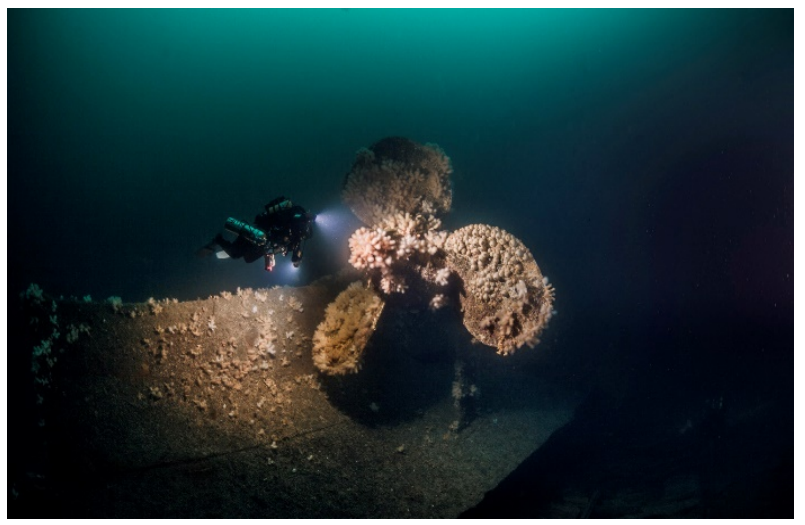

Figure 3: The remaining propeller. Photo: M Tynkkynen.

\section{DATA CAPTURE}

Capturing appropriate images for producing accurate 3D photogrammetric models requires careful planning to ensure systematic overlap of features in the image sequence. The images should be of high enough resolution to allow clear definition of significant features on the target object. Ideally, high resolution photographs with multiple flashguns would produce the optimum quality, however, to cover a target the size of HMS Hampshire (140 metres in length) the time required for this approach would be prohibitive or would require the use of a mini-sub (Drap et al. 2015).

An alternative method is to shoot video footage and sub-sample the frames at intervals that preserve the feature overlap. Although this method limits the image resolution it allows for wider coverage of the subject in a shorter time. This is the method that was employed on the HMS Hampshire project. With restricted access, due to sea states at the location, the considerable depth and restricted dive durations, using video was the most appropriate method. This allowed the team to cover longer distances with reduced chance of missing important details. In the three-day period where visibility was $25+$ metres, the team gathered footage from the stern to the bow along the port side. Recording approximately twenty minutes of video per dive. A total of over fifty hours of video was captured in total during the expedition.

\section{DATA PROCESSING}

Images captured during each dive were initially processed on laptops on the sixty-minute journey back to port. Image sequences were sampled from the video files at five frames per second using Frameshots software. The sequences were then processed using Agisoft Photoscan at normal detail level to test the image alignment. Any areas where details had been missed or images did not overlap sufficiently were identified. These quick tests were used to assist the survey planning for the following days during the daily debrief.

Figure 4 shows the 3D model processed from images collected during dives one and two. The white markers show the camera positions and by implication, the dive routes.

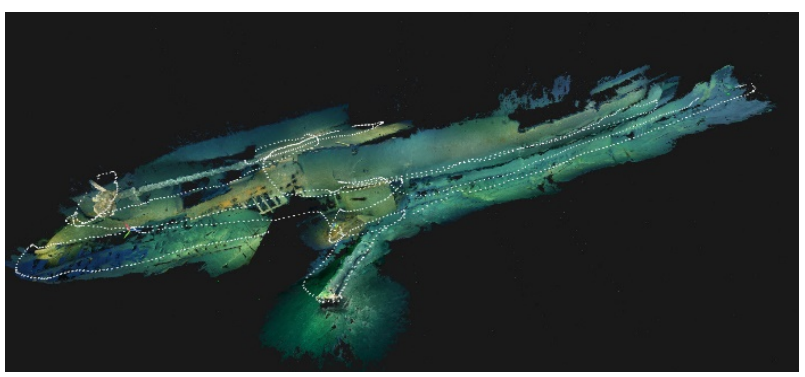

Figure 4: $3 D$ model of portside stern and midships from dive $1 \& 2$.

Higher detail models were processed overnight and shared with the team on board the following day. The process is expedited by utilising faster/multiple CPUs, RAM and GPU support, therefore most of the high-resolution processing was carried out post-expedition on desktop workstations. 


\subsection{Data distortion}

Data distortion can occur when aligning images over a large distance using a long image sequence. This is evident when the 3D model appears to bend when features observed in the original images show straight lines. The effect is caused by small incremental errors in the 3D calculation over distance. To counteract this problem, 1.2 metre rulers were weighted and placed on the seabed at key features of the wreck. These rulers can then be identified in the recorded image sequences and marked as straight edges with known length in the photogrammetry software. At smaller sites than the Hampshire it is possible to capture multiple rulers within the same image and thus avoid the data bending problem. Unfortunately, in our case this was not practical. To cover the full length of the site would have required the placement (and recovery) of approximately eighty rulers on both the port and starboard sides of the wreck.

Figure 5 shows the stern section processed with a higher level of detail. The inverted portside aft casement gun turret can be seen near the mast section extending along the seabed.

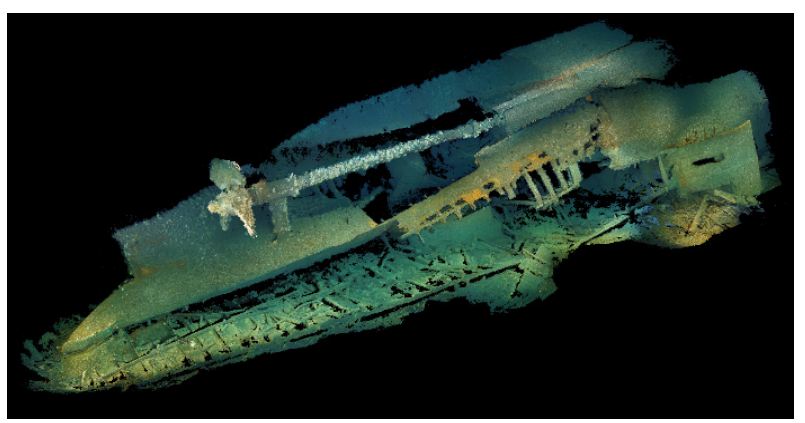

Figure 5: The stern section model in high detail.

Figure 6 is a photograph of the upturned bow section. One of the white 1.2 metre rulers can be seen on the lower foreground of the image. The damage caused by the mine explosion is clearly visible in the upper image.

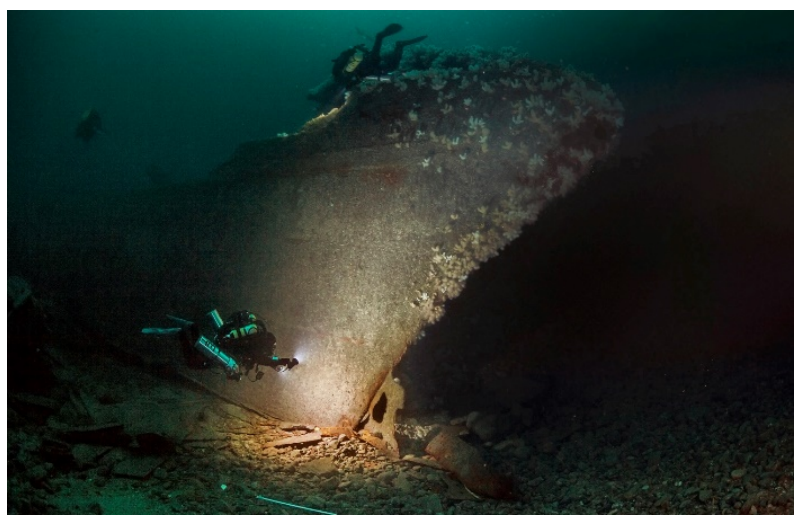

Figure 6: Bow section with mine damage. A white ruler is visible on the foreground.
One effective solution to prevent the bending problem is to break each image sequence down into shorter sections (referred to as chunks in Agisoft Photoscan), run the image alignment process then merge the individual chunks into a single larger chunk. This technique was successfully applied to align data from the first three dives.

A notable feature of the ship was the side turrets with twin casemate guns. The portside casemate gun turret can be seen in Figure 7. The lower gun was removed and the opening sealed to prevent water ingress. This repair has rusted away over time to leave a hole in the structure. The barrel of the upper gun extends along the seabed. The photogrammetry team can be seen illuminating the turret.

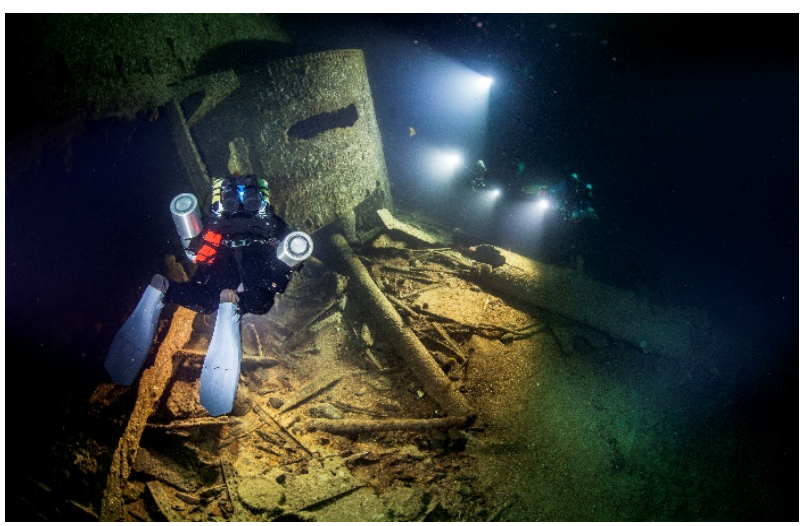

Figure 7: Casemate gun turret. Photo: M Tynkkynen

This feature is accurately reproduced in the $3 D$ photogrammetry model as seen in Figure 8.

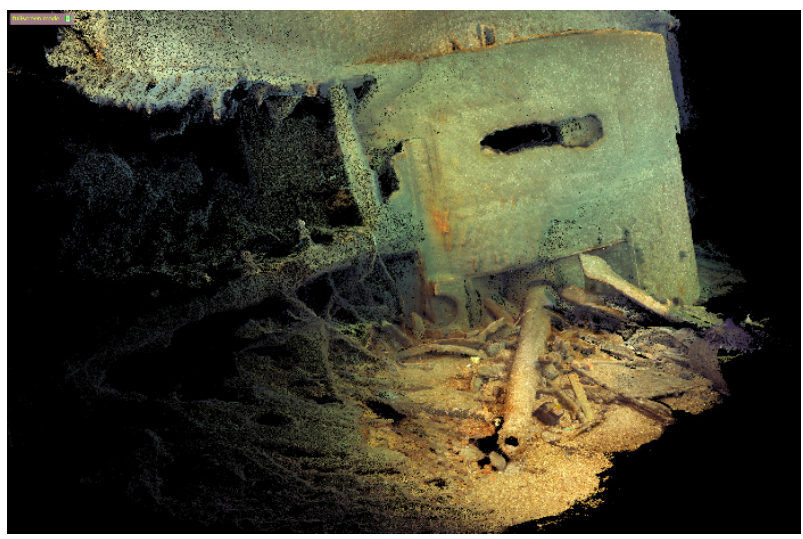

Figure 8: 3D Model of the casemate gun turret.

Many other details along the length of the ship became apparent in the photogrammetry model. Figure 9 shows portholes still attached to hull plating partly obscuring the portside 7.5 inch Mk I gun. 


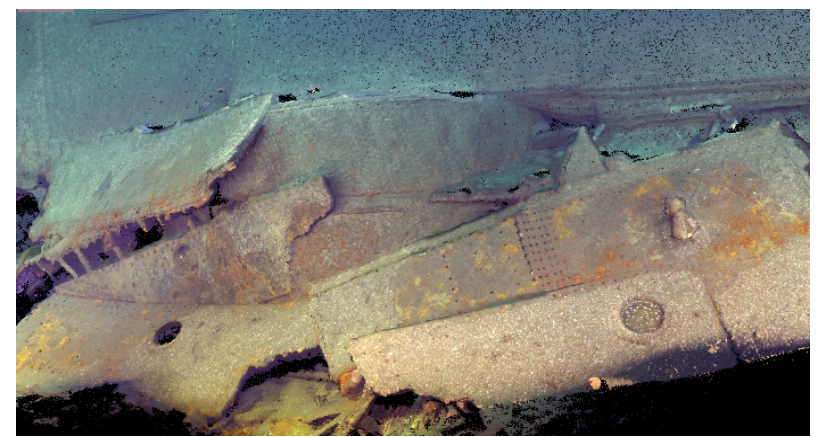

Figure 8: Porthole details with port turret.

The port anchor was discovered still in its hawse pipe on the seabed close to the bow. This can be seen in Figure 9.

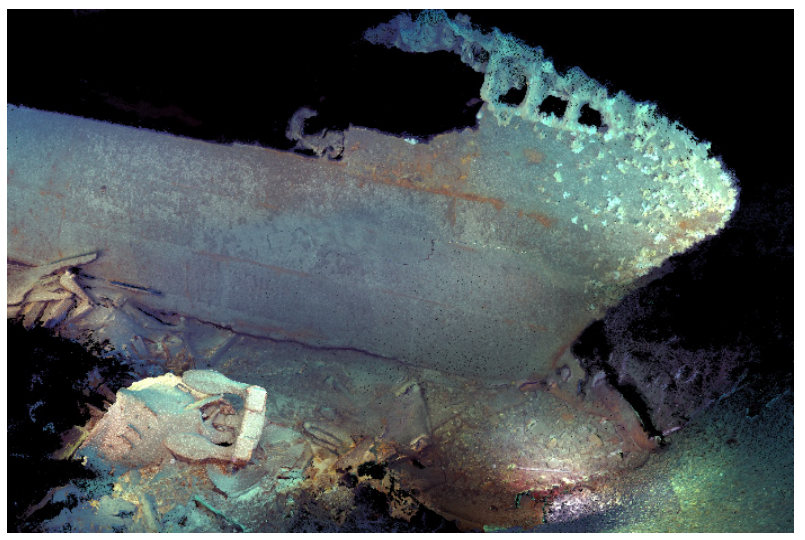

Figure 9: The bow and portside anchor on the seabed.

Figure 10 shows a close-up photograph of the anchor.

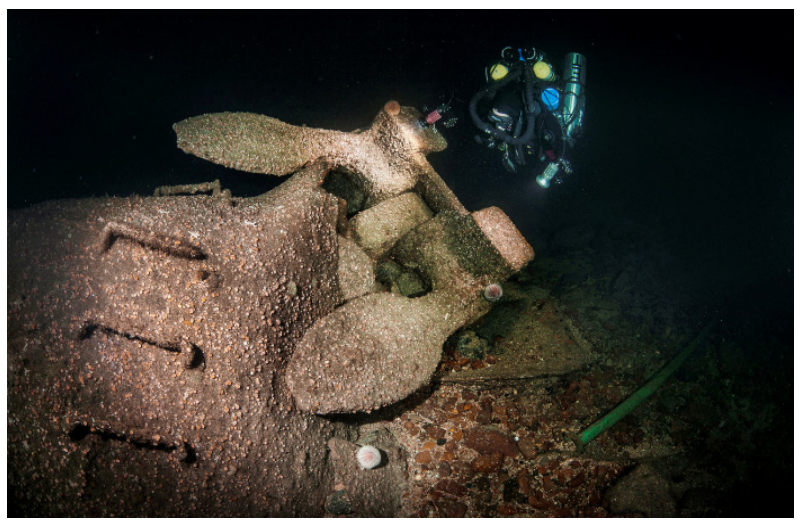

Figure 10: Casemate gun turret. Photo: M Tynkkynen

For comparison, Figure 11 shows the 3D model of the anchor. The ship's hull can be seen in the background.

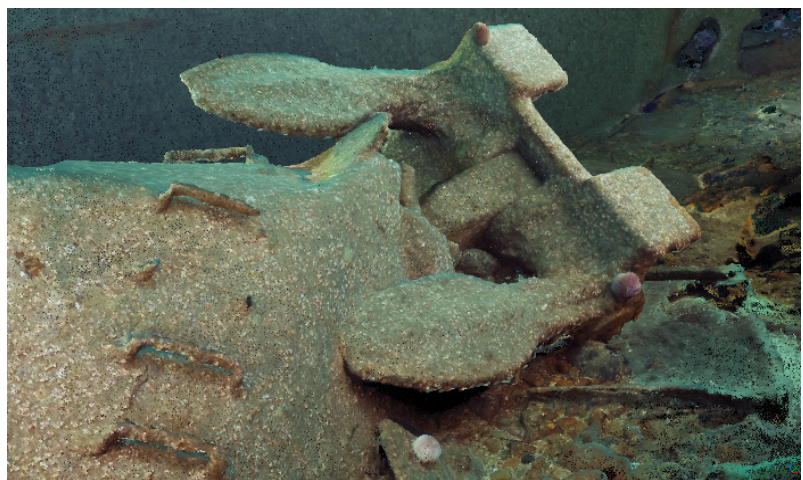

Figure 11: 3D Model of the anchor.

The stern section in Figure 12 shows the portside propeller (as seen in the photograph Figure 3 ). The deck has detached from the hull and lies upturned on the seabed.

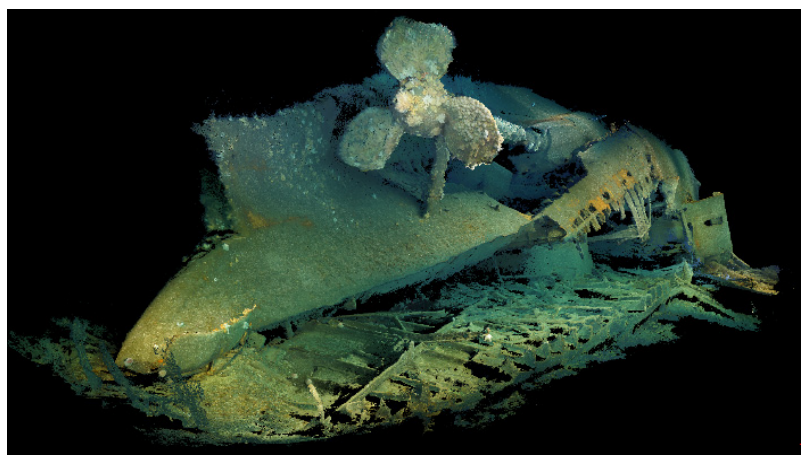

Figure 12: The curved stern section and remaining port side propeller.

Close to the prop shaft, a break in the hull revealed an ammunition store with cases of shells (Figure 13).

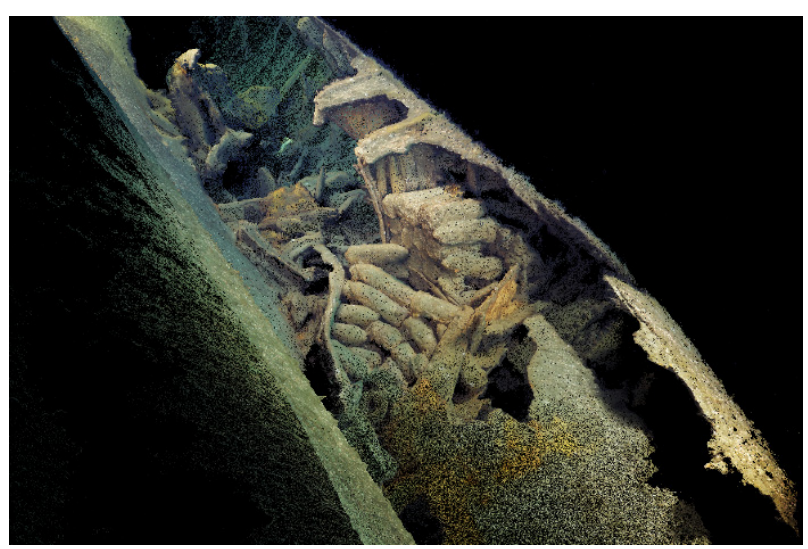

Figure 12: Ammunition store towards the stern.

\section{VR IMPLEMENTATION}

The 3D photogrammetry models provide an opportunity for post-expedition analysis of features of the wreck. In addition the authors were interested in developing a virtual reality (VR) immersive environment that would allow others to 
experience the digital data in a similar way to divers on the expedition.

Experiencing cultural heritage through VR has been a challenge for some decades (Addison 2002). It is only recently that reliable off-the-shelf VR technology such as the Oculus Rift and HTC Vive have become available. The Vive was released commercially in April 2016 and the Oculus Rift in March of the same year.

Many land based sites have been systematically captured for digital preservation, particularly where sites are at risk (CYARK 2003) but few have been adapted successfully as a public facing immersive VR experience.

The HMS Hampshire project provides the 3D data to develop such an experience. The VR element of the project is still a work in progress but early experiments show that recreating the expedition diver's point of view on the wreck for a non-diving audience is achievable. There are physical similarities between wearing a dive mask and a VR headset that help to reinforce the experience. The port side casemate turret section (see Figure 8) was selected as the initial feature to take into VR.

\subsection{Technical challenges}

The initial technical challenge was to prepare the 3D model for the selected interactive platform (Unreal 4 2016). The model output from Photoscan contained a very high polygon count (36 million) which can be handled by Unreal 4 but since the intention was to eventually include the full wreck data, it was considered to be unwieldy at this stage. The data was re-topologised and reduced to 15 million polygons. Unreal can handle texture files of $8 \mathrm{~K}$ but we reduced the turret data textures to $4 \mathrm{~K}$ to allow some leeway for experimentation.

When first loading $3 \mathrm{~d}$ models in .obj format (Autodesk) into Unreal, the software pre-processes the data to optimise for varying levels of detail based on the distance that the camera/viewer is from the object. The next step is to set the scale for the scene. Our intention was to present the turret at life size so that the viewer would see from the diver's point of view.

Following this process custom lighting is added. A low intensity ambient light was placed at the approximate height of the sea's surface to help with orientation. To emulate the illumination from the expedition camera lighting rig, a light source was connected to the camera position and offset by $20 \mathrm{~cm}$ to the left. The light's intensity was set to decrease with distance so that sections of the model close to the user were illuminated whilst more distant sections $A$ third, more focussed, light source was connected to the VR hand held controller so the user could point at details on the model, as though holding a dive torch. A dark blue fog was applied to the scene to accentuate the light drop-off over distance (Figure 13).

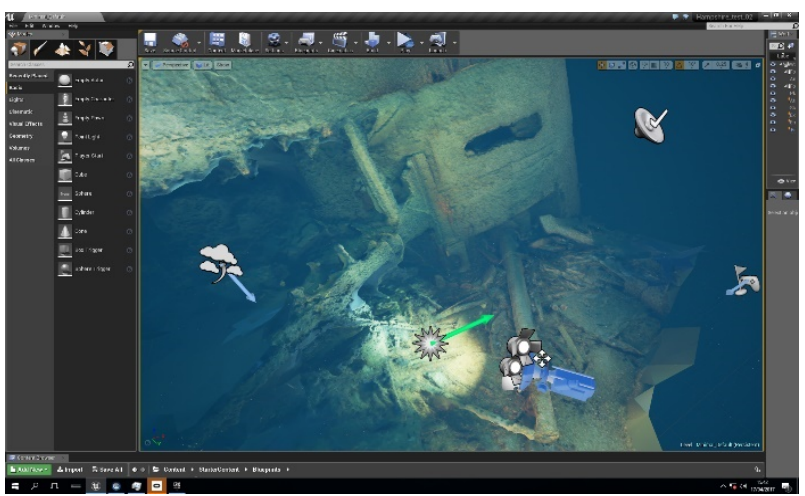

Figure 13: Turret model in Unreal Editor.

The final addition was to add small particle elements into the scene to emulate detritus floating in the water column. Figure 14 shows the view as rendered to the HTC Vive headset and Figure 15 shows a user wearing the VR headset.

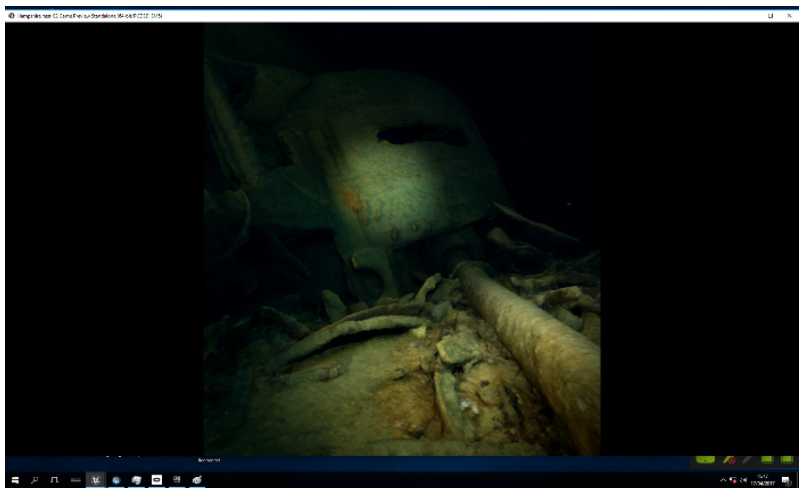

Figure 14: The rendered scene in the HTC Vive.

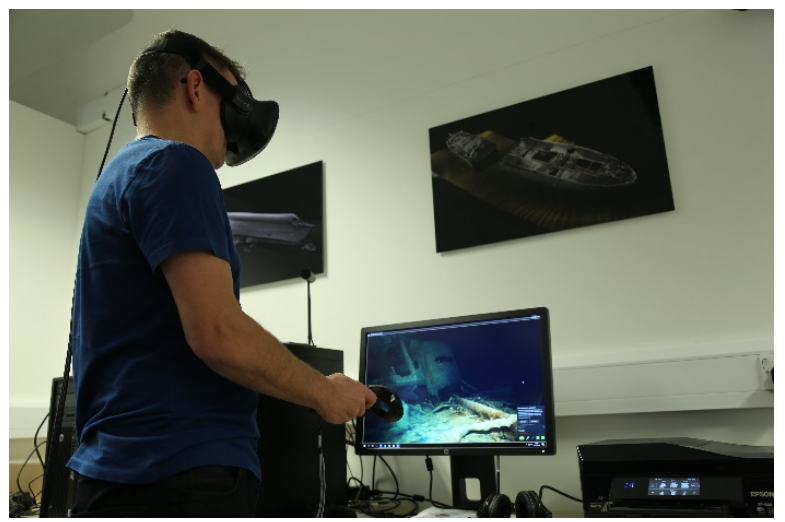

Figure 15: User testing with the HTC Vive. 


\subsection{Full Site Map}

The next step is to use the sonar survey point cloud data from Teledyne and ORCA UHI as a reference to create an overall 3D map of the site to help navigation to the features recreated with Photogrammetry.

\section{CONCLUSIONS}

It is unlikely that the Ministry of Defence will issue another licence to dive the wreck (at least not in the author's lifetime) so this was a unique opportunity to visit an inaccessible military heritage site in uncommonly favourable environmental conditions.

Future plans include public exposition of the completed 3D VR visualisation alongside Marjo Tynkkynen's photographs and other artefacts from the expedition. The Scapa 100 events in Orkney commemorating the centenary of the scuttling of the German WWI High Seas Fleet at Scapa Flow in June 1919, will provide opportunities for the Orkney community to virtually visit HMS Hampshire along with other significant wrecks in the area. HMS Vanguard was surveyed under licence in January 2017 and the German battleship SMS Markgraf which is the main focus of the Citizen Battleship project, a part of the Scapa 100 events.

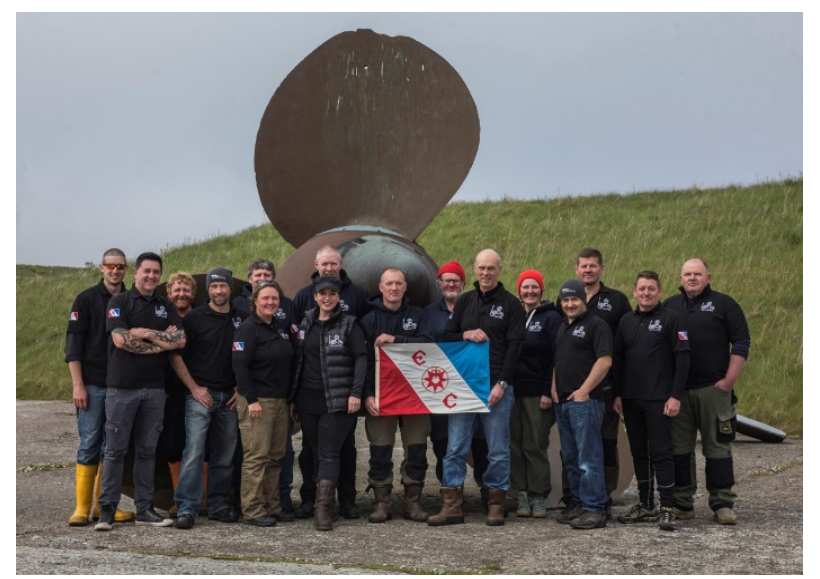

Figure 16: HMS Hampshire team with Flag 192 in front of the propeller Photo: M Tynkkynen

The Hampshire project was recognised as a flagged expedition by The Explorer's Club who allocated Flag 192. Figure 16 shows the project team carrying Flag 192 at Lyness Museum with the salvaged propeller of HMS Hampshire in the background.

\section{REFERENCES}

Addison, A. (2002) Emerging trends in virtual heritage. IEEE Multimedia, 7(2).

Agisoft Photoscan. http://ww.agisoft.com/ (retrieved 12 March 2017).

Autodesk Remake.

https://remake.autodesk.com/about (retrieved 12 March 2017).

Campbell, J (1998) Jutland: An Analysis of the Fighting. Lyons Press, New York.

CYARK. http://www.cyark.org (retrieved 15 March 2017).

Green, S., Bevan, A., and Shapland, M., (2014) A Comparative assessment of structure from motion methods for archaeological research. Journal of Archaeological Science, 46, pp. 173-181. Elsevier.

Drap P, Merad D, Hijazi B, et al. (2015) Underwater Photogrammetry and Object Modeling: A Case Study of Xlendi Wreck in Malta. Menna F, Remondino F, Maas H-G, eds. Sensors (Basel, Switzerland), 15(12).

Frameshots. http://www.frame-shots.om (retrieved 10 March 2017).

Macdonald, R. (2011) Dive Scapa Flow Mainstream Publishing, Edinburgh.

Reality Capture. https://www.capturingreality.com (retrieved 8 April 2017).

Unreal 4. https://www.unrealengine.com/what-isunreal-engine-4 (retrieved 4 April 2017). 